\title{
Analisis Batubara Jenis Antrasit di PTBA Berdasarkan Kandungan Volatile Matter dan Kalori
}

\author{
Yohanes W.M Purba ${ }^{\mathrm{a}}$, Pulung Karo-Karo ${ }^{\mathrm{b}}$, dan Ediman Ginting \\ Jurusan Fisika, Universitas Lampung, Bandar Lampung, Indonesia, 35141
}

\begin{abstract}
Article Information
Article history:

Received 10 Maret 2020

Received in revised form

10Maret 2020

Accepted 30 Maret 2020

Keywords: Coal Anthracite types. Vollatile Matter And Calorie

Abstract

This research Coal is one of the sedimentary fossil fuels that can ignite, is formed from organic sediment, and the remains of plants are then formed through the process of coalification. The main element consists of carbon, hydrogen, and oxygen. The formation of coal has certain conditions and only occurs in certain eras throughout geological history. The carbon age was approximately 340 million years ago. In the Permian Age or the Paleozoic era, 270 million also formed the most productive coal which is almost the entire coal deposit (black coal) in other parts of the earth. In this study we conducted at the Laboratory of PT. Bukit Asam tbk. Observation Results in the Study of Average Volatile Matter 19.11, Max Volatile Matter value 38.34, Min Vollatie Matter value 11.34. And the Average Calorie Result of $7578.5 \mathrm{Kacl} / \mathrm{Kg}$, Max Calorie Value of $8046 \mathrm{Kcal} / \mathrm{Kg}$. In this study, it was proved that coal samples were Anthracite types.
\end{abstract}

\begin{tabular}{|c|c|}
\hline Informasi Artikel & Abstrak \\
\hline $\begin{array}{l}\text { Proses artikel: } \\
\text { Diterima } 10 \text { Maret } 2020 \\
\text { Diterima dan direvisi dari } \\
10 \text { Maret } 2020 \\
\text { Accepted } 30 \text { Maret } 2020\end{array}$ & $\begin{array}{l}\text { Batubara merupakan salah satu bahan bakar fosil sedimen yang dapat } \\
\text { terbakar,terbentuk dari endapan organik, dan sisa-sisa tumbuhan kemudian } \\
\text { terbentuk melalui proses pembatubaraan.Unsur utamanya terdiri dari karbon, } \\
\text { hydrogen, dan oksigen.Pembentukan batubara memiliki kondisi tertentu dan } \\
\text { hanya terjadi pada era tertentu sepanjang sejarah geologi. Zaman karbon kira- } \\
\text { kira } 340 \text { juta tahun yang lalu.Pada Zaman Permian atau era Paleozoikum, } 270 \\
\text { juta juga terbentuk batubara yang Paling produktif dimana hamper seluruh } \\
\text { deposit batubara (black coal) dibelahan bumi lain. Pada penelitian ini kita } \\
\text { lakukan di Laboratorium PT. Bukit Asam tbk. Hasil Pengamatan pada Penelitian }\end{array}$ \\
\hline $\begin{array}{l}\text { Kata kunci: } \\
\text { Batubara Jenis Antrasit, } \\
\text { Vollatile Matter dan Kalori }\end{array}$ & $\begin{array}{l}\text { Rerata Vollatile Matter 19.11, nilai Max Vollatile Matter } 38.34 \text {, nilai Min Vollatie } \\
\text { Matter 11.34. Dan Hasil Kalori Rerata } 7578.5 \mathrm{Kacl} / \mathrm{Kg} \text {, Nilai Max Kalori } 8046 \\
\text { Kcal/Kg. Pada penelitian ini membuktikan bahwa sampel batubara adalah jenis } \\
\text { Antrasit. }\end{array}$ \\
\hline
\end{tabular}

\section{Pendahuluan}

Batubara merupakan salah satu bahan bakar fosil sedimen yang dapat terbakar,terbentuk dari endapan organik, dan sisa-sisa tumbuhan kemudian terbentuk melalui proses pembatubaraan. Unsur utamanya terdiri dari karbon, hidrogen dan oksigen. Pembentukan batubara memiliki kondisi tertentu dan hanya terjadi pada era tertentu sepanjang sejarah geologi. Zaman karbon kira-kira 340 juta tahun yang lalu.Pada Zaman Permian atau era Paleozoikum, 270 juta juga terbentuk batubara yang Paling produktif dimana hampir seluruh deposit batubara (black coal) (Baaqy and Arias, 2013).

Secara ringkas ada 2 tahapan proses terjadi, yakni: Tahap Diagenetik atau Biokimia dimulai pada saat material tanaman terdeposisi hingga lignit terbentuk, proses perubahan ini adalah kadar air, tingkat oksisdasi dan gangguan biologis yang dapat menyebabkan proses pembusukan dan kompaksi material organic serta membentuk gambut. Tahapan Malihan atau Geokimia : meliputi proses perubahan dari lignit menjadi bituminous dan akhirnya antrasit (Prasetyo, 2016).

Volatie Matter adalah kandungan zat terbang yang terkandung dalam batubara. Zat yang terkandung dalam volatitel matter ini biasanya adalah gas hidrokarbon dan gas metana .Volatile matter atau kandungan zat terbang

* Corresponding author.

E-mail addres: (a)wendipurba17@gmail.com, (b) pulungkarokaro@gmail.com 
yang tinggi menyebabkan juga batubara mudah terbakar. Nilai volatile matter yang tinggi menyebabkan resiko dan menimbulkan adanya bahaya ledakan.Volatile matter terdiri dari bahan-bahan yang mudah terbakar seperti hydrogen,karbon monoksida,dan metana.Moisture atau air yang terkandung pada batubarajuga berpengaruh terhadap volatile matter ( Tupamahu, 2011).

Kalori adalah satu parameter penentu kualitas batubara ialah nilai kalornya, yaitu seberapa banyak energi yang dihasilkan per satuan massanya. Nilai kalor batubara diukur menggunakan alat yang disebut bom kalorimeter. Bom calorimeter terdiri dari 2 unit yang digabungkan menjadi satu alat. Unit pertama ialah unit pembakaran di mana batubara dimasukkan ke dalam bom lalu diinjeksikan oksigen kemudian tersebut dimasukkan kedalam bejana. Batubara dibakar dengan adanya suplai udara/oksigen sebagai pembakar water handling .Unsur utamanya terdiri dari,karbon, hydrogen,dan oksigen. dapat menganalisa volatile metternya ( Richard, 2000).

\section{Metode Penelitian}

Penelitian ini dilaksanakan di PT. Bukit Asam tbk. Bahan yang digunakan yaitu: Batubara Antrasit dan menganalisa Batubara dengan menggunakan parameter Volatile Matter dan Kalori.

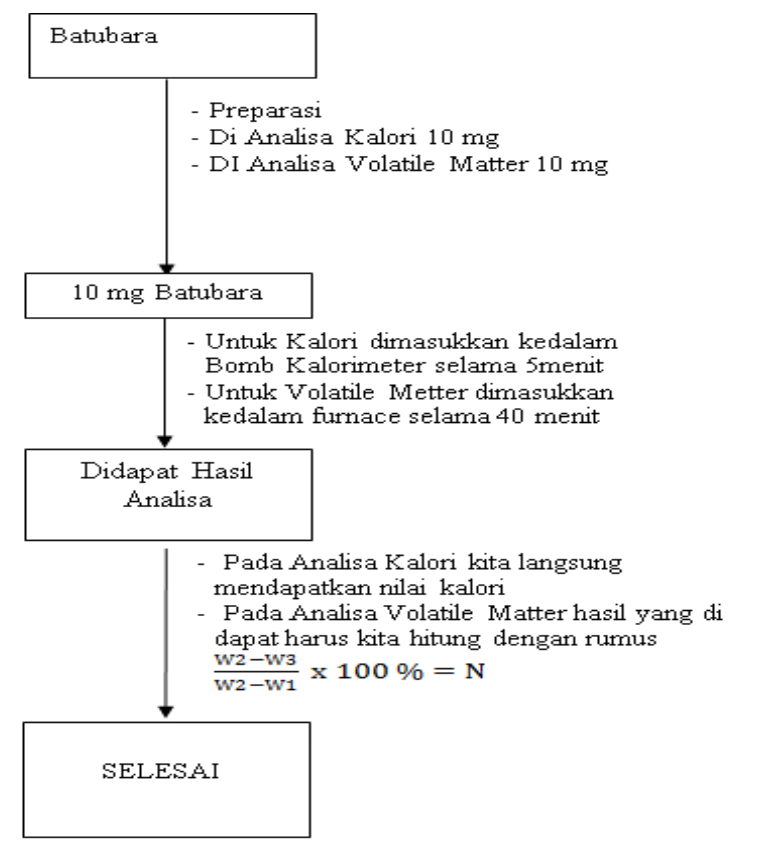

Gambar 1. Metode penelitian

\section{Hasil Dan Pembahasan}

\subsection{Hasil Analisa Batubara Jenis Antrasit}

Pada penelitian di PT.Bukit Asam Berdasarkan referensi penulis diperoleh bahwa batubara jenis antrasit memiliki total sampel pada bulan Desember 2019-Februari 2020 mengelompokan 60 sampel yang dianalisa tersebut. Pada bulan Desember 2020 ada 20 sampel batubara antrasit, pada bulan januari sampel batubara antrasit paling banyak sampelnya 32 sampel batubara antrasit, di bulan februari paing sedikit sampel antrasit ada 8 sampel batubara antrasit dapat dilihat pada Tabel 1.

Pada Analisa Sampel Batubara Jenis Antrasit dihasilkan Rerata Vollatile Matter 19.11, nilai Max Vollatile Matter 38.34, nilai Min Vollatie Matter 11.34. Dan Hasil Kalori Rerata $7578.5 \mathrm{Kacl} / \mathrm{Kg}$, Nilai Max Kalori 8046 Kcal/Kg.Pada penelitian ini membuktikan bahwa sampel batubara adalah jenis Antrasit penelitian ini sesuai dengan yang dilakukan oleh (Anisa, 2017) dan (Novrizqa, 2013) dapat dilihat pada Tabel 2. 
Purba Y.W.M, Karo-Karo P, Ginting E, 2020 Analisis Batubara Jenis Antrasit Di Ptba Berdasarkan Kandungan Volatile Matter dan Kalori , Journal of Energy Material and Instrumentation Technology, Vol. 1 No. 1, 2020

Tabel 1. Hasil Analisa Batubara Jenis Antrasit Periode 20 Desember 2019 25 Januari 2020 (PT. Bukit Asam, 2020)

\begin{tabular}{|c|c|c|c|}
\hline \multirow[b]{2}{*}{ NO } & \multirow[b]{2}{*}{$\begin{array}{l}\text { NOMOR } \\
\text { SAMPEL }\end{array}$} & \multicolumn{2}{|c|}{ PARAMETER } \\
\hline & & $\begin{array}{l}\text { VM (*) } \\
\%(\mathrm{adb})\end{array}$ & $\begin{array}{l}\mathrm{GCV}\left({ }^{*}\right) \\
\mathrm{Kcal} / \mathrm{kg}(\mathrm{adb})\end{array}$ \\
\hline 1 & $3420-12-2019$ & 37.67 & 7124 \\
\hline 2 & $3473-12-2019$ & 19.87 & 7420 \\
\hline 3 & $3477-12-2019$ & 20.25 & 7427 \\
\hline 4 & $3479-12-2019$ & 18.75 & 7873 \\
\hline 5 & $3483-12-2019$ & 18.84 & 7850 \\
\hline 6 & $3485-12-2019$ & 18.49 & 7843 \\
\hline 7 & $3486-12-2019$ & 16.72 & 7676 \\
\hline 8 & $3489-12-2019$ & 17.76 & 7786 \\
\hline 9 & $3491-12-2019$ & 16.86 & 7773 \\
\hline 10 & 3494-12-2019 & 17.21 & 7888 \\
\hline 11 & $3497-01-2020$ & 19.68 & 7564 \\
\hline 12 & $3498-01-2020$ & 16.4 & 7816 \\
\hline 13 & $3499-01-2020$ & 19.07 & 7523 \\
\hline 14 & $3502-01-2020$ & 12.98 & 7411 \\
\hline 15 & $3537-01-2020$ & 12.79 & 7576 \\
\hline 16 & $3550-01-2020$ & 13.25 & 7418 \\
\hline 17 & $3569-01-2020$ & 21.74 & 7828 \\
\hline 18 & $3581-01-2020$ & 13.95 & 7273 \\
\hline 19 & $3604-01-2020$ & 14.85 & 7393 \\
\hline 20 & $3626-01-2020$ & 38.34 & 7405 \\
\hline 21 & $3637-01-2020$ & 34.43 & 7679 \\
\hline 22 & $3652-01-2020$ & 36.57 & 7686 \\
\hline 23 & $3669-01-2020$ & 35.56 & 7433 \\
\hline 24 & $3702-01-2020$ & 14.79 & 7448 \\
\hline 25 & $3712-01-2020$ & 11.34 & 7548 \\
\hline 26 & $3717-01-2020$ & 17.13 & 7447 \\
\hline 27 & $3842-01-2020$ & 11.95 & 7248 \\
\hline 28 & $3845-01-2020$ & 18.97 & 7331 \\
\hline 29 & $3845-01-2020$ & 17.31 & 7697 \\
\hline 30 & $3858-01-2020$ & 17.39 & 7410 \\
\hline
\end{tabular}

Tabel 2. Rerata Nilai Volatile Matter

\begin{tabular}{ccc}
\hline RERATA & 19.11 & 7578.5 \\
\hline MAX & 38.34 & 8946 \\
\hline MIN & 11.34 & 7124
\end{tabular}




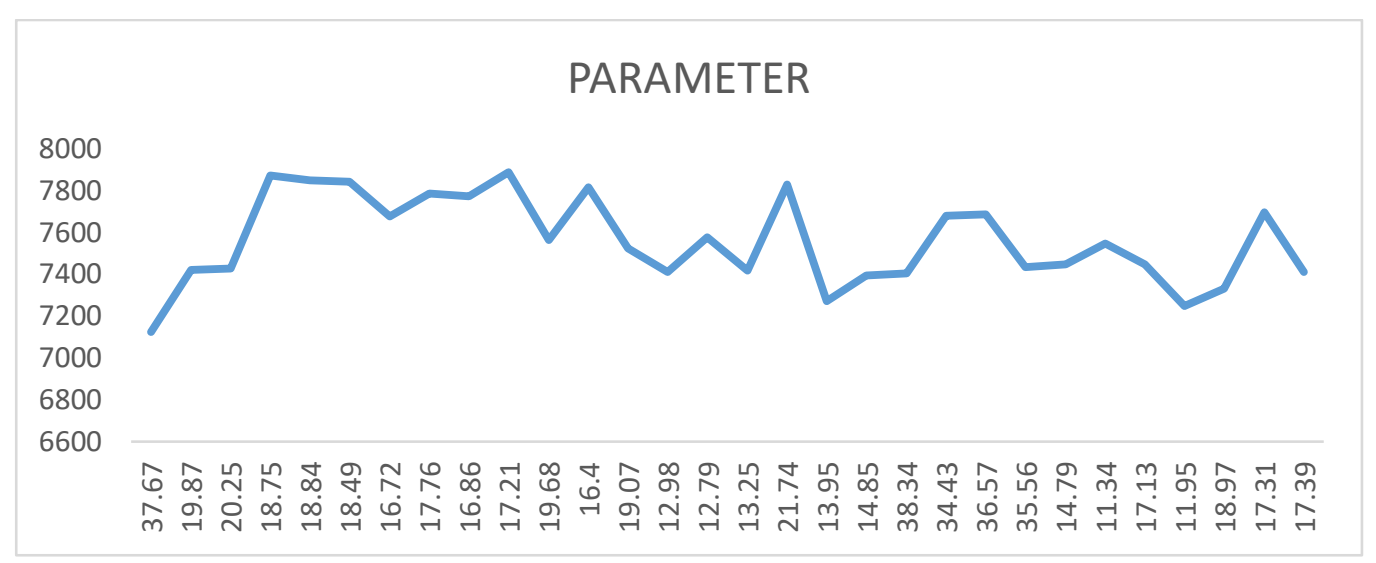

Gambar 2. Grafik Kandungan Volatile Matter terhadap Nilai Kalori.

Dari grafik pada Gambar 2 memiliki kalori $7548 \mathrm{Kcal} / \mathrm{Kg}$ dengan kadar volatile Matter 1.34\%, ini membuktikan bahwa semakin rendah kadar volatile matter maka nilai kalornya semakin tinggi, sedangkan nomor 23 , memiliki kalor $7433 \mathrm{Kcal} / \mathrm{Kg}$ dengan kadar volatile matternya 35.56\%, kondisi ini juga membenarkan teori semakin besar kadar volatile matternya maka akan semakin kecil nilai kalor pada batubara (Astuti et all, 2007). Namun terdapat juga data yang tidak sesuai dengan teori yang ada, ditunjukkan pada nomor 1, yang memiliki nilai volatile matter $37.67 \%$ dengan kalor $7124 \mathrm{Kcal} / \mathrm{Kg}$, sedangkan pada sample no. 20 , memiliki volatile matter $38.34 \%$ dengan nilai kalor $7045 \mathrm{Kcal} / \mathrm{Kg}$ sesuai dengan penelitian (Jati, 2009).

\section{Kesimpulan}

Berdasarkan penelitian yang sudah dilakukan maka dapat disimpulkan bahwa nilai maksimum yang dihasilkan Vollatile Matter sebesar 38.34 dan nilai Minimum 11.34. Nilai kalori yang dianalisa Maksimum 7578.5 $\mathrm{Kcal} / \mathrm{Kg}$ dan Minimum $7124 \mathrm{Kca} / \mathrm{Kg}$, nilai Vollatile Matter pada batubara ternilai tinggi mempengaruhi nilai kalori yang akan menjadi semakin rendah, sebaliknya jika nilai kandungan Vollatile Matter rendah maka akan membuat nilai kalori menjadi lebih tinggi.

\section{Daftar Pustaka}

Anisa, 2017, 'Determinasi Seberapa Kuat Pengaruh Nilai Kandungan Abu Terhadap Nilai Zat Terbang dan Nilai Kalori Dalam Persentasi', Jurnal GEOSAPTA, Vol. 3, No. 2, pp. 127-131.

Astuti, Jumaeri, W, Westari, W. T. P, 2007. 'Preparasi dan Karakterisasi Zeolit Dari Abu Layang Batubara Secara Alkali Hidrotermal', Jurnal Jurusan Kimia, Vol. 11, No. 1, pp. 38-44.

Baaqy, Arias, G, 2013, 'Pengeringan Low Range Coal Dengan Menggunakan Metode Pemanasan Tanpa Kehadiran Oksigen, Jurnal Teknik POMITS, Vol. 2, No. 2, pp. 228-233.

Erna Komariah, Wulan, 2012, 'Peningkatan Kualitas Batubara Indonesia Peringkat Rendah Melalui Penghilangan Moisture Dengan Pemanasan Gelombang Mikro', Fakultas Teknik Universitas Indonesia, Depok.

Jati, S. N, 2009, Tipe Pola Sebaran dan Kemenurusan Batubara Antiklin Palaran, UPN, Yogyakarta.

Prasetyo, Agus, 2016, 'Optimasi Pencampuran Batubara Melalui Simulasi Berdasarkan Kriteria Parameter Batubara', Jurnal HIMASAPTA, Vol.1, No.1, pp. 11-16.

Nukman, 2008, 'Pengaruh Pencampuran Batubara Semi Antrasit dan Bituminus Terhadap Karakteristik Pembakarannya Dengan Oksigen Murni, Jurnal Rekayasa Mesin, Vol. 8, No. 2, pp. 77-83.

Novrizqa, Prabowo, 2013, 'Karakteristik Pengeringan Batubara Pada Fluidized Bed Cool Dyer Terhadap Pengaruh Variasi Temperatur Air Heater Dengan Tube Heater Tersusun Staggered dan Perbandingan Volume Chamber dan Volume Batubara Sebesar 50\%', Jurnal Teknik POMITS, Vol. 2, No. 1, pp. 56-61.

Prasetyo, Agus, 2016, 'Optimasi Pencampuran Batubara Melalui Simulasi Berdasarkan Kriteria Parameter Batubara', Jurnal HIMASAPTA, Vol.1, No.1, pp. 11-16.

PT. Bukit Asam, 2003, Kandungan Pada Vollatile Matter , Jurnal Bukit PT. Bukit Asam, Tanjung Enim 